\title{
FORMULATION AND DEVELOPMENT OF TRANSDERMAL DRUG DELIVERY SYSTEM OF ETHINYLESTRADIOL AND TESTOSTERONE: IN VITRO EVALUATION
}

\author{
SHIKHA BAGHEL CHAUHAN ${ }^{*}$, TANVEER NAVED ${ }^{b}$, NAYYAR PARVEZ ${ }^{c}$
}

\author{
aDepartment of Pharmaceutics, Amity Institute of Pharmacy, Amity University, Noida, Uttar Pradesh, India, bDepartment of \\ Pharmaceutics, Amity Institute of Pharmacy, Amity University, Noida, Uttar Pradesh, India, 'Department of Pharmacy, School of Medical \\ and Allied Sciences, Galgotias University, Greater Noida, UP, India \\ Email: shikha.pharma@gmail.com
}

Received: 17 Jul 2018, Revised and Accepted: 19 Nov 2018

\begin{abstract}
Objective: The combination therapy of ethinylestradiol and testosterone in post-menopausal females has shown improved sexual response and libido. The present studies were designed to develop a suitable matrix-type transdermal drug delivery system (TDDS) of ethinylestradiol and
\end{abstract} testosterone using the polymer chitosan.

\begin{abstract}
Methods: Five formulations (ET1 to ET5) were developed by varying the concentration of polymer and keeping the drug load constant. Physical parameters and drug excipient interaction studies were evaluated in all the formulations. In vitro skin permeation profiles of ethinylestradiol and testosterone from various formulations were simultaneously characterized in a thermostatically controlled modified Franz Diffusion cell using HPLC. Based on the physical parameters and in vitro skin permeation profile formulation ET3 containing $30 \mathrm{mg} / \mathrm{ml}$ of chitosan was found to be the best and chosen for further studies. Optimized formulation was subjected to in vivo pharmacokinetic analysis in rats using ELISA.
\end{abstract}

Results: Stability profile of patch formulation ET3 depicted stability up to 3 mo. One week skin irritation evaluation in rats indicated that formulation ET3 was nonirritating. Combination transdermal patch across rat skin showed a maximum release of 92.936 and $95.03 \%$ in $60 \mathrm{~h}$ with a flux of 2.088 and $21.398 \mu \mathrm{g} / \mathrm{cm}^{2} \mathrm{~h}$ for ethinylestradiol and testosterone respectively.

Conclusion: The net result of this study is the formulation of a stable, non-irritating transdermal patch of ethinylestradiol and testosterone, with good bioavailability and can be used as Estrogen Replacement Therapy (ERT) in postmenopausal women.

Keywords: Estradiol, Testosterone, Transdermal matrix patches, Chitosan, Formulation development

(c) 2019 The Authors. Published by Innovare Academic Sciences Pvt Ltd. This is an open access article under the CC BY license (http://creativecommons.org/licenses/by/4.0/) DOI: http://dx.doi.org/10.22159/ijap.2019v11i1.28564

\section{INTRODUCTION}

The concept of delivering drugs through the skin for systemic treatment of diseased states is gaining increasingly great importance due to its advantages [1]. The advantages of TDDS are bypassing of hepatic first-pass metabolism, enhancement of therapeutic efficiency, prolonged duration of action of potent drugs with short plasma half-life and maintenance of steady plasma or serum level of the drug. However, transdermal delivery is limited to drugs having low doses, low melting points, and molecular weights and solubility of greater than $1 \mathrm{~m} \mathrm{~g} / \mathrm{ml}$ in both water and mineral oil [2].

Ethinylestradiol and testosterone both play a significant role in regulating female sexual function. The most common complaints associated with decreased estrogen and/or testosterone levels are decreased desire and libido, vaginal dryness and lack of sexual arousal in postmenopausal females [3-13]. The estimated proportion of women who can be classified as having low sexual desire ranges from 7 to $33 \%$, depending on the population studied and the definition being used $[8,14]$. Due to a hormonal deficiency in postmenopausal women, Hypoactive Sexual Desire Disorder (HSDD) is commonly reported [3, 15-17]. Estrogen replacement therapy improves sexual function in females in conjunction with testosterone. In plasma, testosterone is largely bound to Serum Hormone Binding Globulin (SHBG). Estrogen Replacement Therapy (ERT) increases SHBG production: therefore, it is plausible that postmenopausal women treated with exogenous estrogen have less available free testosterone than untreated women [18]. This may subsequently lead to a decrease in sexual function in women who are treated with ERT [18-21]. Postmenopausal women who have failed to correct their sexual function with ERT alone can improve their sexual response treated additionally with testosterone $[3,10$, 19-22]. Moreover, ethinylestradiol and testosterone possess most of the ideal physicochemical and biological properties to be formulated into a transdermal patch type delivery system like small $t^{1} \frac{1}{2}$, (in minutes), small daily dose in (in $\mu \mathrm{g} /$ day) $[10,23]$ and hepatic firstpass effect upon oral administration. But so far, no work related to the development of transdermal patches of ethinylestradiol and testosterone in combination has been reported. The present investigation was designed to develop a suitable matrix patch [24] type TDDS for ethinylestradiol and testosterone employing varied amounts of chitosan. Chitosan is widely acknowledged to be nontoxic even at relatively high concentrations in vivo and in vitro.

Chitosan is a cationic polymer that exhibits several unique properties, which are desirable features of TDDS. Chitosan may act as penetration enhancer to improve the permeability of drugs across the underlying tissue by its effects on tight junctions [25-28]. The aim of the present study was to optimize the concentration of polymer for a suitable delivery system in terms of in vitro and in vivo skin permeation of drugs and to find out the best possible concentration of polymer, which may be chosen for further studies.

\section{MATERIALS AND METHODS}

\section{Materials}

Chitosan and ethinylestradiol were received as a gift sample from Central Cochin Fisheries Ltds., Cochin and Ontop Pharmaceuticals ltd., Bangalore. Testosterone was purchased from Sigma Aldrich, India. methanol (HPLC grade) (SD Fine Chemical Ltd, Mumbai, disodium hydrogen phosphate A. R grade, potassium dihydrogen orthophosphate (CDH (P) Ltd New Delhi), gum acacia (Pioneer Chemical Co., Delhi) were also procured. All chemicals were used as received without any further purification.

\section{Preparations of films}

Transdermal films of ethinylestradiol $(2.5 \mathrm{mg})$ and testosterone $(25$ $\mathrm{mg}$ ) were prepared by varying the concentration of chitosan $(20,25$, 30,35 and $40 \mathrm{mg} / \mathrm{ml}$ ) and keeping the drug load constant. Bioadhesive film was prepared by a solvent casting method. The 
chitosan was accurately weighed and transferred to a $10 \mathrm{ml}$ beaker; to this $5 \mathrm{ml}$ of $4 \%,(\mathrm{v} / \mathrm{v})$ lactic acid (as a solvent and permeation enhancer) was added. The beaker was kept on magnetic stirrer to dissolve the polymer. The mixture was stirred continuously stirred to prevent the formation of lumps of polymer and stirring was continued till a clear solution was obtained. To this $25 \mathrm{mg}$ of testosterone was added and the stirring was continued. After $24 \mathrm{~h}$ of stirring. $2.5 \mathrm{mg}$ of ethinylestradiol was added, and the stirring was continued for another $24 \mathrm{~h}$. The resulting solution was then transferred onto the Teflon coated mould $\left(15 \mathrm{~cm}^{2}\right)$. The mould was covered with an inverted funnel to control the rate of evaporation of the solvent system and kept undisturbed overnight for drying. The dried patches were kept in desiccators until use.

\section{Drug-polymer interaction study}

The physicochemical compatibility between ethinylestradiol and testosterone and polymers used in the films was studied by using Fourier transform-infrared (FT-IR-8400, Shimadzu Co., Japan) spectroscopy. The pellatization was done by the $\mathrm{KBr}$ pellet method. The FT-IR spectra were recorded in the wavelength region between 4000 and $400 \mathrm{~cm}^{-1}$. The spectra obtained for ethinylestradiol and testosterone and physical mixtures of ethinylestradiol and testosterone with polymers were compared.

\section{Differential scanning calorimetry}

About $5 \mathrm{mg}$ of sample was weighed and crimped into an aluminum pan and analyzed at scan range from $0{ }^{\circ} \mathrm{C}-300^{\circ} \mathrm{C}$ at the heating rate of $5{ }^{\circ} \mathrm{C} / \mathrm{min}$ under a nitrogen flow of $25 \mathrm{ml} / \mathrm{min}$

\section{Physical characteristics of the prepared films}

The thickness of each patch was measured at different sites using Membrane Thickness Gauge, and the average thickness was calculated. Patches were evaluated for their physical appearance and graded as opaque/transparent/smooth/wrinkled/moist/dry/flexible/tough/sti cky/non-sticky.

Each patch was cut into six patches of $1 \mathrm{~cm}^{2}$ area and weighed. The average weight was calculated, and percentage deviation of each 1 $\mathrm{cm}^{2}$ patch from average weight was determined. Folding endurance was determined by repeatedly folding the film at the same place until it broke. The number of times the film could be folded at the same place without breaking was the folding endurance value. Flatness was determined as thee longitudinal strips were cut out from each film. The length of each strip was measured and the variation in length because of non-uniformity in flatness was measured by determining percent constriction with $0 \%$ constriction equivalent to $100 \%$ flatness [29].

Percentage of constriction $=\left(\mathrm{I}_{1}-\mathrm{I}_{2}\right) / \mathrm{I}_{2} \times 100$

Where, $l_{1}=$ initial length of each strip and

$\mathrm{I}_{2}=$ final length of each strip

\section{Percentage moisture absorption}

The films were weighed accurately and placed in the desiccator containing $100 \mathrm{ml}$ of saturated solution of potassium chloride, which maintains $84.34 \% \mathrm{RH}$ at $25{ }^{\circ} \mathrm{C}$. After $3 \mathrm{~d}$ the films were taken out and weighed. The percentage moisture absorption was calculated using the following formula [2]-

Percentage of moisture content $=\mathrm{X}-\mathrm{Y} / \mathrm{Y} \times 100$

Where, $\mathrm{X}=$ initial weight, $\mathrm{Y}=$ final weight.

\section{Drug content uniformity}

An accurately cut patch of $1 \mathrm{~cm}^{2}$ area was taken and added to the beaker containing $10 \mathrm{ml}$ saline solution. The beaker was kept for 24 $\mathrm{h}$ with occasional shaking. The samples were analyzed for drug content using HPLC at 244 and at $280 \mathrm{~nm}$ for testosterone and ethinylestradiol respectively [39].

\section{In vitro skin permeation studies}

The in vitro skin permeation studies of ethinylestradiol and testosterone from TDDS though rat skin was conducted using a modified Franz Diffusion cell. Protocols for all animal experiments were approved by the Institutional Animal Ethics Committee. Methanol: phosphate Buffer saline, $\mathrm{pH} 7.4$ in the ratio of 7.3 was used as a receptor fluid in the receptor compartment of the cell. Rat's abdominal skin was excised, hair was removed using scissors, and fatty tissues attached to dermis were removed carefully [40, 41]. The skin was mounted between donor and receiver compartment of the diffusion cell having capacity $20 \mathrm{ml}$, with the epidermis facing upward into the donor compartment. The test film of $1.5 \mathrm{~cm}^{2}$ area was placed on the acclimatized skin. The bathing solution in receiver compartment was agitated with a magnetic stirrer at a temperature of $37 \pm 1{ }^{\circ} \mathrm{C}$ maintained thermostatically. Samples ( $\mathrm{l} \mathrm{ml}$ in each case) were withdrawn at regular intervals, and fresh receptor fluid was added to maintain a constant volume of receptor fluid. The Samples were analyzed at 280 and $244 \mathrm{~nm}$, for ethinylestradiol and testosterone respectively using HPLC (LC Solutions Shimadzu, Japan) and drug contents were determined from the calibration curve. Calibration curves for both the drugs were obtained using HPLC equipped with a Prominence diode-array detector. A purospher STAR, merck RP 18C Pre-packed column $(5 \mu \mathrm{m}, 250 \mathrm{~mm}$ $4 \mathrm{~mm}$ i. d) was used as an analytical column. Methanol: water (70:30) combination after optimization was used as the mobile phase at a flow rate oflml $/ \mathrm{minl} \mathrm{ml} / \mathrm{min}$. The analytical column was maintained at $37^{\circ} \mathrm{C}$ the same temperature as for drug release and skin permeation studies to minimize the potential drug precipitation in the column. A $20 \mu \mathrm{l}$ sample volume was injected each time though a manual injector using Hamilton microlitre syringe. The chomatographic peaks for ethinylestradiol and testosterone were well resolved at retention times (RT) at 6.6 and $8.6 \mathrm{~min}$. respectively.

\section{Stability evaluation}

Stability studies were performed for 3 mo using optimized formulation ET3. All the stability samples (packed in aluminum foil) were prepared in triplicates and were kept at two stability testing conditions: viz. Accelerated $\left(40 \pm 2 \quad{ }^{\circ} \mathrm{C} / 75 \% \pm 5 \% \mathrm{RH}\right)$ and Intermediate $\left(30 \pm 2{ }^{\circ} \mathrm{C} / 65 \% \pm 5 \% \mathrm{RH}\right)$ as per (ICH) Q1AR2 guidelines [30]. Stability samples were evaluated for drug excipient interaction and in vitro permeation through human cadaver epidermis at the following time points; initial, 1st, 2nd and 3rd month [42].

\section{Skin irritation studies}

The optimized transdermal patches were evaluated for primary skin irritation studies on rats. All the experimental procedures were approved by the Institutional Animal Ethics Committee (IAEC). All the experimental procedures were carried out in accordance with the committee for the purpose of control and supervision of experiment on animal guidelines (125/2013/CPCSEA). Wistar rat's hairs were removed by shaving from the dorsal area one day before the test. The rats were divided into 4 groups $(n=6)$. Group, I served as the control (without any treatment), Group II received optimized medicated transdermal patch, Group III received a blank transdermal patch and Group IV applied with a $0.8 \% \mathrm{v} / \mathrm{v}$ aqueous solution of formalin as a standard irritant [31]. A new patch, or new formalin solution, was applied at Ist, 4th and at 7th day. The patch was secured using an adhesive tape. These patches were covered with an occlusive covering to approximate the condition of use. Finally, the application sites were graded for any sign of erythema or edema according to a visual scoring scale.

\section{RESULTS AND DISCUSSION}

Transdermal Therapeutic Systems are self-contained, discrete dosage forms which, when applied to the intact skin, deliver the $\operatorname{drug}(\mathrm{s})$, though the skin, at a controlled rate to the systemic circulation. Testosterone has been combined with ethinylestradiol since ERT alone leads to a decrease in free testosterone level. TDDS have been designed for controlled drug delivery with the intention of maintaining constant plasma levels.

The physicochemical studies like the percentage moisture absorption, flatness, folding endurance etc. provide information regarding the stability of the formulations. Formulations ET 1-5 contained fixed amount of testosterone $(25 \mathrm{mg})$ and ethinylestradiol $(2.5 \mathrm{mg}$ ) and polymer (chitosan) concentration was varied from 20$40 \mathrm{mg} / \mathrm{ml}$ respectively. The area of the patch was $15 \mathrm{~cm}^{2}$ (table 1$)$. 
The physical appearance of the various formulations in terms of their transparency, smoothness, flexibility, stickiness, homogeneity and opaque properties were recorded, and formulation ET3 was found to be uniform, translucent, slightly sticky and flexible. The percentage of moisture absorption, average thickness, and weight varied to a small extent in all formulations studied.

Table 1: Physicochemical evaluations of formulations

\begin{tabular}{|c|c|c|c|c|c|c|c|}
\hline \multirow{2}{*}{$\begin{array}{l}\text { Formulation } \\
\text { code }\end{array}$} & \multirow{2}{*}{$\begin{array}{l}\text { Uniformity of } \\
\text { weight } \\
(\mathrm{mg}) / \mathrm{cm}^{2} \pm \mathrm{SD}^{\mathrm{a}}\end{array}$} & \multirow{2}{*}{$\begin{array}{l}\text { Thickness } \\
(\mathrm{mm}) \pm \mathrm{SD}^{\mathrm{a}}\end{array}$} & \multirow{2}{*}{$\begin{array}{l}\text { Flatness } \\
(\%)\end{array}$} & \multirow{2}{*}{$\begin{array}{l}\text { Folding } \\
\text { endurance }\end{array}$} & \multirow{2}{*}{$\begin{array}{l}\text { Percentage } \\
\text { moisture } \\
\text { absorption }\end{array}$} & \multicolumn{2}{|c|}{ Average drug content $(\%)^{a}$} \\
\hline & & & & & & Testosterone & Ethinylestradiol \\
\hline ET1 & $21.5 \pm 0.36$ & $0.070 \pm 0.008$ & 100 & $372 \pm 8$ & 15 & $92 \pm 4.3$ & $96 \pm 4.8$ \\
\hline ET2 & $22.6 \pm 0.72$ & $0.074 \pm 0.007$ & 100 & $381 \pm 9$ & 18 & $87 \pm 4.8$ & $94 \pm 5.4$ \\
\hline ET3 & $22.9 \pm 0.39$ & $0.076 \pm 0.008$ & 100 & $390 \pm 11$ & 16 & $93 \pm 4.2$ & $96 \pm 6.2$ \\
\hline ET4 & $23.2 \pm 0.45$ & $0.081 \pm 0.009$ & 100 & $367 \pm 7$ & 20 & $88 \pm 5.3$ & $95 \pm 5.8$ \\
\hline ET5 & $23.2 \pm 0.45$ & $0.083 \pm 0.005$ & 100 & $400 \pm 9$ & 23 & $89 \pm 5.1$ & $91 \pm 3.7$ \\
\hline
\end{tabular}

amean $\pm S D, n=3$

\section{Matrices properties}

The weight variations of the patches were in the range of 20.6 $\mathrm{mg} / \mathrm{cm}^{2}$ to $22.9 \mathrm{mg} / \mathrm{cm}^{2}$ for 5 formulations, the difference in weight variation was due to the addition of polymer in different ratios which influence weight of patches. The results are given in table 1.

The thickness of the transdermal patches ET l-ET5 for 5 different polymer ratios varied from $0.070 \pm 0.008 \mathrm{~mm}$ to $0.083 \pm 0.005 \mathrm{~mm}$. The maximum difference between the thicknesses of patches was $0.013 \mathrm{~mm}$, which indicates that all the prepared patches were of nearly uniform thickness. The results are given in table 1 .

All the formulations ET1-ET5 showed 100\% flatness which indicates $0 \%$ constriction of the formulated patches (table 1). Test results indicated that all the patches can withstand to rupture and would maintain their integrity with general folding when used. The folding endurance values lie in between 372 and 400 and were measured manually. The value was found to be high in patches containing a higher amount of the chitosan. The prepared transdermal patches showed good tensile strength and there was no sign of cracking in the prepared transdermal film. Mechanical properties of a polymer matrix were improved by the use of polymers.

Tensile strength lies in between $372 \mathrm{~g} / \mathrm{cm} 2$ and $400 \mathrm{~g} / \mathrm{cm} 2$, the difference in values were due to the composition of polymer used. Also, there was an increase in the tensile strength with increasing concentration of chitosan. Highest tensile strength was observed in ET5, and this might be due to the highest concentration of hydrophilic polymer used and as the concentration decreased from ET5 to ET1tensile strength got decreased. The results are given in table 1.

The percentage moisture absorption was calculated which was found to be as 15 to $23 \%$ for ET1-ET5 respectively (table 1 ). There was an increase in moisture absorption with an increase in the amount of hydrophilic polymer, chitosan. Similarly, the thickness and weight of patch were found to be increased accordingly.

The drug content varied due to polymers which were added in different concentrations. As the polymer concentration increases, the bond formation between the drug molecules and polymer molecules increases which will retard the drug release. The drug content of ethinylestradiol in formulations ETl-ET5 varied from 91$96 \%$ (table l) the drug content of testosterone in formulations ET1ET5 varied from 88-96\%. (table 1). This demonstrates the homogenous distribution of the drugs.

The FTIR and DSC scans of the patch containing drugs and patch without drug were obtained to assess any interaction between drug and excipients. On analysis of the FTIR spectra of the pure drug and the medicated formulation, no major difference was observed in the absorption peak pattern. The DSC of patch gave an endothermic peak of testosterone at $146{ }^{\circ} \mathrm{C}$ (pure drug-149 ${ }^{\circ} \mathrm{C}$ ), and an endothermic peak of ethinylestradiol at $184{ }^{\circ} \mathrm{C}$ (pure drug-185.13 ${ }^{\circ} \mathrm{C}$ ) and this confirmed the purity of drug sample used. The DSC data suggested that possibly there was no chemical interaction between drugs with patch forming polymer/materials. The HPLC spectrum showed absorption maxima at $244 \mathrm{~nm}$ for testosterone and an absorption maximum at $280 \mathrm{~nm}$ for ethinylestradiol with RT-8.6 and 6.6 min respectively (fig. 1 and 2).

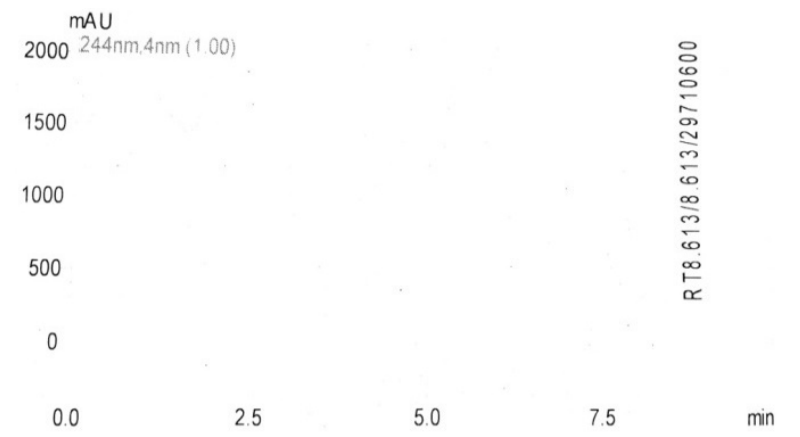

Fig. 1: HPLC chromatogram of testosterone showing retention time (RT) and Area under curve (AUC) at $244 \mathrm{~nm}$

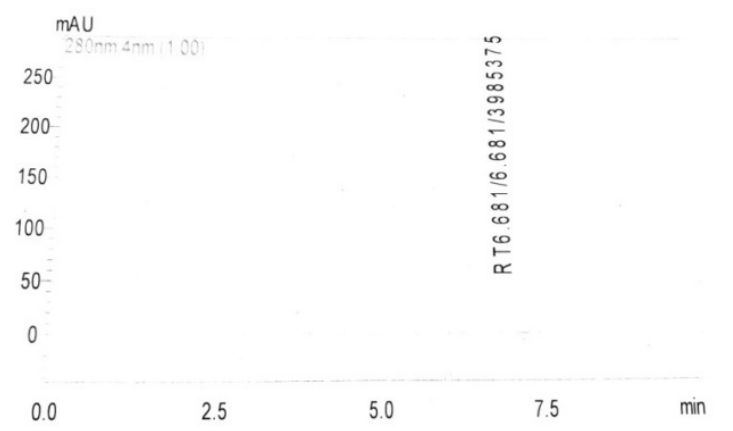

Fig. 2: HPLC chromatogram of ethinylestradiol showing a retention time (RT) and Area under the curve (AUC) at $280 \mathrm{~nm}$

\section{Drug release}

The permeability of ingredients was evaluated using modified Franz diffusion Cell. The formulation showed the variable release pattern. The process of drug release in most of the controlled release devices including transdermal patches is governed by diffusion In vitro release profile of ethinylestradiol and testosterone across rat skin was maximum from the formulation ET3, with $92.936 \%$ of ethinylestradiol at the end of' $60 \mathrm{~h}$ (fig. 3) and $95.033 \%$ of testosterone at the end of $60 \mathrm{~h}$ (fig. 4) with flux of 2.088 for ethinylestradiol and $21.398 \mu \mathrm{g} /\left(\mathrm{cm}^{2} \mathrm{~h}\right)$ for testosterone. The in vitro skin permeation studies using cadaver skin as rate limiting membrane for formulation ET3 showed a maximum release of $80.456 \pm 1.64 \%$ ethinylestradiol in $60 \mathrm{~h}$ with a flux of $1.938 \pm 10.52 \mu \mathrm{g} /\left(\mathrm{cm}^{2} \mathrm{~h}\right)$ and 
$79.51+1.05 \%$ testosterone in $60 \mathrm{~h}$ with a flux of $18.673 \pm 0.8 \mathrm{l}$ $\mu \mathrm{g} /\left(\mathrm{cm}^{2} \mathrm{~h}\right)$ (table 2). The studies indicated that the overall permeation rate in rat skin is higher than that in the cadaver skin.

This showed that the formulations with increased concentrations of chitosan resulted in sustained release of the drug up to a certain level and furthermore decreased due to excess polymer concentration which resulted in high encapsulation of drug. Formulations ET1, ET 2, ET 4 and ET5) with varied polymer concentration, showed a constant increase and then decrease in the cumulative drug release due to drug degradation by the excess moisture content and uptake.

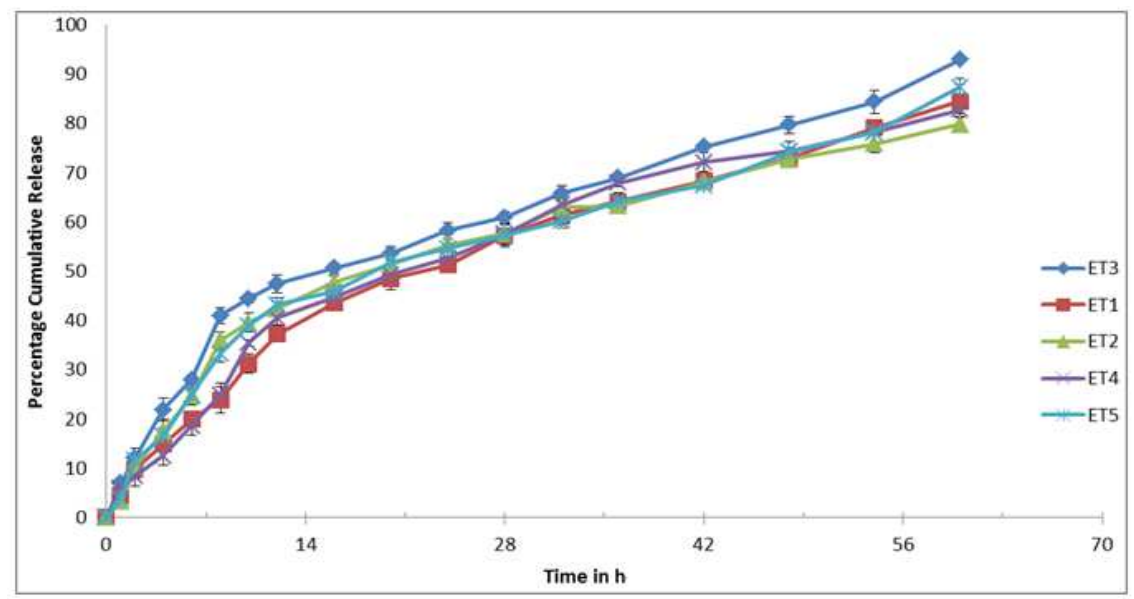

Fig. 3: Comparative permeation profiles of Ethinylestradiol from different patch formulations across rat skin. $m e a n \pm S D, n=3$

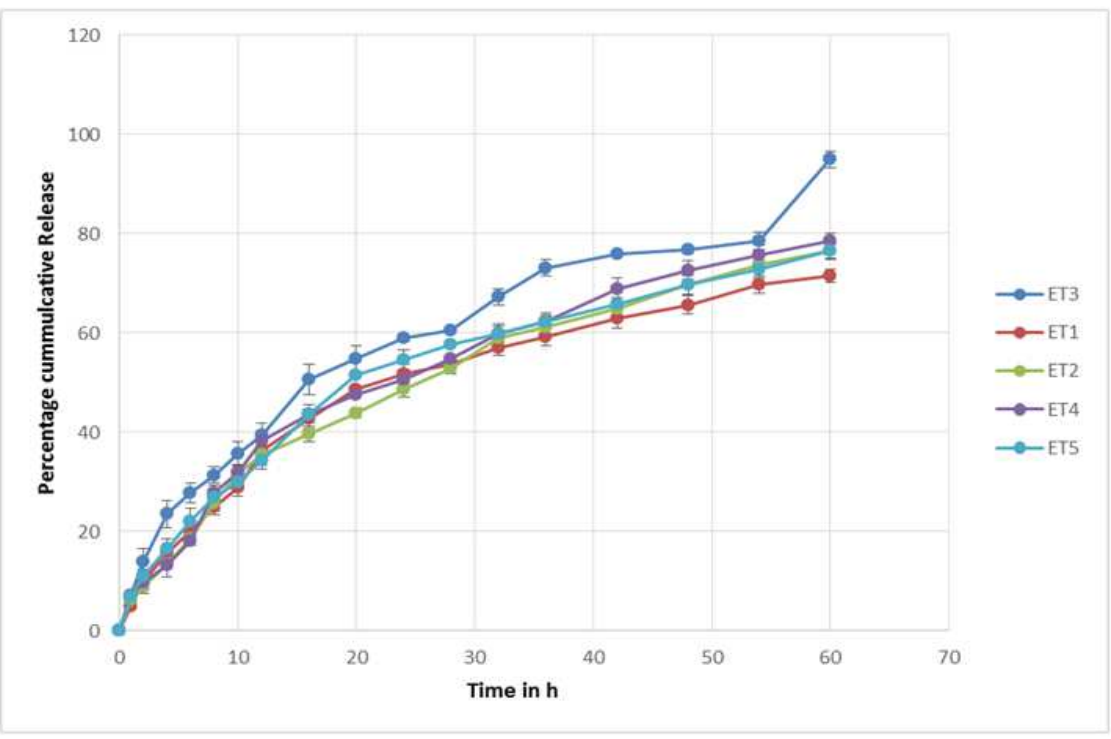

Fig. 4: Comparative permeation profiles of testosterone from different patch formulations across rat skin, mean \pm SD, $n=3$

Table 2: Release kinetics

\begin{tabular}{lllllll}
\hline \multirow{2}{*}{ Formulation } & Zero order $\mathbf{R}^{\mathbf{*}}$ & & First order $\mathbf{R}^{\mathbf{*}}$ & & Higuchian plot $\mathbf{R}^{\mathbf{*}}$ \\
\cline { 2 - 7 } & Ethinylestradiol & Testosterone & Ethinylestradiol & Testosterone & Ethinylestradiol & Testosterone \\
\hline ET1 & 0.881 & 0.937 & 0.852 & 0.894 & 0.992 & 0.998 \\
ET2 & 0.943 & 0.905 & 0.847 & 0.868 & 0.997 & 0.986 \\
ET3 & 0.903 & 0.922 & 0.943 & 0.879 & 0.9767 & 0.985 \\
ET4 & 0.974 & 0.903 & 0.921 & 0.864 & 0.984 & 0.979 \\
ET5 & 0.956 & 0.887 & 0.936 & 0.898 & 0.978 & 0.996 \\
\hline
\end{tabular}

$* \mathrm{R}^{2}$ values are determination coefficients

On the basis of physicochemical parameters and drug release content out of five formulations made, ET3 (150 mg chitosan) was selected for further studies and was considered as optimized formulation. Comparison of $\mathrm{R}^{2}$ values was made in order to assess the nature of the release profile of the formulations. The respective
$\mathrm{R}^{2}$ values for formulation ET I to ET5 was found to be $0.881,0.943$, $0.903,0.974$ and 0.956 respectively for zero order release plot of ethinylestradiol and $0.937,0.905,0.922,0.903$ and 0.887 respectively for zero order release plot of testosterone. (table 2) High $\mathrm{R}^{2}$ values with zero order plots indicating a zero order release 
pattern from the formulations. Optimized formulation (ET3) was further subjected to first order and Higuchian regression parameters to find a best-fit model for the formulation. The regression coefficient value of the first-order plot for formulation ET3 was 0.94 ethinylestradiol and 0.8795 testosterone. The regression coefficient for Higuchian plot was 0.9767 ethinylestradiol and 0.9851 testosterone. Linear curves were obtained on plotting the graphs of cumulative percentage drug released versus square root of time suggesting Higuchian matrix diffusion mechanism of drug release from the TDDS formulation. The results are depicted in table 2. The drug release kinetics studies showed that all formulations were governed Higuchian model and the release was non-Fickianmediated. Regression analysis of the in vitro permeation curves was carried out. The slope of the curve obtained after plotting the mean cumulative amount released per patch versus time was taken as the in vitro release for ethinylestradiol and medroxyprogesterone acetate.

\section{Skin irritation studies}

The optimized transdermal formulation ET3 was evaluated for skin irritation studies on rats. The patches were removed after $48 \mathrm{~h}$, and the area was examined for any signs of skin sensitivity or irritation and the fresh patches were secured at the same site at $1^{\text {st }}, 4^{\text {th }}$ and $7^{\text {th }}$ day which is a modification over the method of Draize et al., 1946 [38]. No signs of erythema and edema were observed in case of patch group. There was a significant difference $(\mathrm{P}<0.01)$ observed between the patch and the formalin treated group (table 3 ).

Table 3: Visual scores of skin irritation amongst various groups

\begin{tabular}{lllll}
\hline Group & I & II & III & IV \\
\cline { 2 - 5 } & $\begin{array}{l}\text { Control } \\
\text { (No treatment) }\end{array}$ & $\begin{array}{l}\text { Blank } \\
\text { (Blank patch) }\end{array}$ & $\begin{array}{l}\text { Medicated } \\
\text { (Medicated patch) }\end{array}$ & $\begin{array}{l}\text { Formalin } \\
\text { (0.8\% aq. Solution) }\end{array}$ \\
\hline Eythema & $0.00 \pm 0.00$ & $1.167 \pm 0.408^{* *}$ & $1.50 \pm 0.548^{* *}$ & $3.333 \pm 0.516$ \\
Edema & $0.00 \pm 0.00$ & $1.167 \pm 0.753^{* *}$ & $1.333 \pm 0.816^{* *}$ & $3.167 \pm 0.753$ \\
\hline
\end{tabular}

All values are reported as (mean value \pm SEM) $(n=6),{ }^{* *}$ represents $\mathrm{P}<0.01$ (very significant) in comparison to group IV

\section{Stability}

The optimized ET3 patches were properly packed in aluminum foil and kept for stability studies as per ICH guidelines. Transdermal patch was studied for three months at intermediate and accelerated conditions (table 3). The physicochemical analysis, in vitro permeation across cadaver skin, FTIR and DSC analysis at the end of each month were conducted to assess the stability of formulations during intermediate and accelerated conditions.

Table 3: Permeation profiles (Mean \% cumulative release \pm SD) ${ }^{a}$ of patch ET3 during accelerated stability study across cadaver skin

\begin{tabular}{|c|c|c|c|c|c|c|c|c|}
\hline \multirow{2}{*}{$\begin{array}{l}\text { Time } \\
\text { (h) }\end{array}$} & \multicolumn{2}{|l|}{ Zero month } & \multicolumn{2}{|l|}{ First month } & \multicolumn{2}{|c|}{ Second month } & \multicolumn{2}{|c|}{ Third month } \\
\hline & $\mathbf{E}$ & $\mathbf{T}$ & $\mathbf{E}$ & $\mathbf{T}$ & $\mathbf{E}$ & $\mathbf{T}$ & $\mathbf{E}$ & $\mathbf{T}$ \\
\hline 0 & $0.00 \pm 0.00$ & $0.00 \pm 0.00$ & $0.00 \pm 0.00$ & $0.00 \pm 0.00$ & $0.00 \pm 0.00$ & $0.00 \pm 0.00$ & $0.00 \pm 0.00$ & $0.00 \pm 0.00$ \\
\hline 1 & $6.97 \pm 1.02$ & $6.48 \pm 1.79$ & $6.87 \pm 0.91$ & $6.47 \pm 0.62$ & $6.84 \pm 0.87$ & $6.47 \pm 2.35$ & $6.84 \pm 1.58$ & $6.46 \pm 1.64$ \\
\hline 2 & $10.19 \pm 0.34$ & $11.25 \pm 1.36$ & $10.02 \pm 0.96$ & $11.2 \overline{5} \pm 0.50$ & $10.00 \pm 0.88$ & $11.2 \overline{5} \pm 2.51$ & $10.00 \pm 1.76$ & $11.25 \pm 1.48$ \\
\hline 4 & $19.84 \pm 0.41$ & $18.53 \pm 0.62$ & $19.78 \pm 1.07$ & $18.51 \pm 0.99$ & $19.77 \pm 0.94$ & $18.50 \pm 1.29$ & $19.75 \pm 1.63$ & $18.50 \pm 1.69$ \\
\hline 6 & $23.99 \pm 0.55$ & $23.18 \pm 1.57$ & $22.95 \pm 1.08$ & $23.12 \pm 1.82$ & $21.94 \pm 1.57$ & $23.11 \pm 1.48$ & $21.91 \pm 2.57$ & $23.10 \pm 1.34$ \\
\hline 8 & $30.95 \pm 0.48$ & $22.36 \pm 2.99$ & $30.95 \pm 0.25$ & $22.35 \pm 0.95$ & $30.78 \pm 2.84$ & $22.34 \pm 1.64$ & $30.71 \pm 2.18$ & $22.33 \pm 1.82$ \\
\hline 10 & $37.44 \pm 1.12$ & $30.47 \pm 3.05$ & $37.44 \pm 0.39$ & $30.46 \pm 3.78$ & $37.31 \pm 1.28$ & $30.46 \pm 1.98$ & $37.31 \pm 2.65$ & $30.44 \pm 2.15$ \\
\hline 12 & $42.15 \pm 0.89$ & $34.31 \pm 3.24$ & $42.15 \pm 0.44$ & $34.32 \pm 2.45$ & $42.02 \pm 1.36$ & $34.30 \pm 0.65$ & $42.00 \pm 2.95$ & $34.30 \pm 2.65$ \\
\hline 16 & $43.35 \pm 0.67$ & $40.99 \pm 2.58$ & $42.98 \pm 0.70$ & $40.99 \pm 3.48$ & $42.24 \pm 1.59$ & $40.97 \pm 0.48$ & $42.23 \pm 1.52$ & $40.96 \pm 2.94$ \\
\hline 20 & $49.57 \pm 0.78$ & $44.71 \pm 2.46$ & $49.57 \pm 0.69$ & $44.70 \pm 2.51$ & $49.45 \pm 1.24$ & $44.68 \pm 0.95$ & $49.45 \pm 1.87$ & $44.65 \pm 3.54$ \\
\hline 24 & $53.22 \pm 1.10$ & $48.24 \pm 0.73$ & $53.22 \pm 0.61$ & $48.21 \pm 1.68$ & $53.22 \pm 2.65$ & $48.20 \pm 0.69$ & $53.21 \pm 1.94$ & $48.20 \pm 0.65$ \\
\hline 28 & $52.54 \pm 1.58$ & $50.25 \pm 0.88$ & $53.01 \pm 0.54$ & $50.23 \pm 1.45$ & $53.02 \pm 2.58$ & $50.23 \pm 1.25$ & $53.00 \pm 1.68$ & $50.23 \pm 0.97$ \\
\hline 32 & $59.49 \pm 1.91$ & $55.36 \pm 066$ & $59.43 \pm 0.81$ & $55.34 \pm 1.82$ & $59.42 \pm 1.92$ & $55.32 \pm 1.59$ & $5942 \pm 1.81$ & $55.30 \pm 0.65$ \\
\hline 36 & $63.96 \pm 2.27$ & $62.16 \pm 1.83$ & $63.96 \pm 0.70$ & $62.15 \pm 1.24$ & $63.95 \pm 1.43$ & $62.13 \pm 1.86$ & $63.93 \pm 1.37$ & $62.11 \pm 1.57$ \\
\hline 42 & $71.44 \pm 2.59$ & $65.72 \pm 1.08$ & $71.44 \pm 2.10$ & $65.72 \pm 1.76$ & $71.43 \pm 1.53$ & $65.70 \pm 1.67$ & $71.43 \pm 1.52$ & $65.70 \pm 1.83$ \\
\hline 48 & $73.12 \pm 2.63$ & $66.83 \pm 0.79$ & $73.12 \pm 2.24$ & $66.83 \pm 1.84$ & $73.11 \pm 2.64$ & $66.81 \pm 1.23$ & $73.10 \pm 0.69$ & $66.80- \pm 1.94$ \\
\hline 54 & $77.54 \pm 1.55$ & $68.51 \pm 0.40$ & $77.54 \pm 0.62$ & $68.50 \pm 0.62$ & $77.53 \pm 2.84$ & $68.49 \pm 1.51$ & $77.53 \pm 0.94$ & $68.481 .64 \pm$ \\
\hline 60 & $80.45 \pm 0.67$ & $79.51 \pm 1.64$ & $80.45 \pm 1.36$ & $79.50 \pm 1.36$ & $80.05 \pm 2.41$ & $79 \pm 2.59$ & $80.00 \pm 1.51$ & $78.80 \pm 1.83$ \\
\hline 66 & $78.21 \pm 1.56$ & $72.54 \pm 2.11$ & $78.21 \pm 0.99$ & $72.52 \pm 0.64$ & $78.20 \pm 1.58$ & $72.50 \pm 1.94$ & $78.18 \pm 1.67$ & $72.50 \pm 1.24$ \\
\hline 72 & $74.24 \pm 0.98$ & $66.28 \pm 1.97$ & $74.24 \pm 0.98$ & $66.28 \pm 1.47$ & $74.21 \pm 2.02$ & $66.25 \pm 1.85$ & $74.20 \pm 1.59$ & $66.23 \pm 1.06$ \\
\hline
\end{tabular}

${ }^{a}$ mean $\pm S D, n=3$.

\section{CONCLUSION}

Testosterone has been combined with ethinylestradiol as ERT (Estrogen Replacement Therapy) alone leads to a decrease in free for testosterone level. Total testosterone production decreases by around $25 \%$ after menopause. Since ethinylestradiol and testosterone both play a significant role in regulating female sexual function and hence, been successfully combined in a single patch. Amongst the five formulations studied, formulation ET3 showed release profile of above $90 \%$ at the end of $60 \mathrm{~h}$ with $92.93 \%$ of ethinylestradiol and $95.03 \%$ of testosterone across rat skin and $80.45 \%$ of ethinylestradiol and $79.51 \%$ of testosterone across cadaver skin. The optimized patch was physicochemical stable and had non-irritating nature when applied on rat skin. Further, it can be reasonably concluded that chitosan polymer in $30 \mathrm{mg} / \mathrm{ml}$ concentration is better suited over other concentrations used for the development of TDDS of ethinylestradiol and testosterone for HSDD in postmenopausal women. The net result of this study is the formulation of a stable, non-irritating transdermal patch of ethinylestradiol and testosterone, with good bioavailability and the optimized formulation (ET3) may be used for further pharmacodynamics studies in suitable animal models.

\section{ACKNOWLEDGEMENT}

The authors are thankful to Amity University, Noida for their support and providing the facilities to carry the research work. 


\section{AUTHORS CONTRIBUTIONS}

All the author have contributed equally

\section{CONFLICT OF INTERESTS}

Declared none

\section{REFERENCES}

1. Guy RH, Hadgraft J. Selection of drug candidates for transdermal drug delivery. transdermal drug delivery: developmental issues and research initiatives. marcel deeker inc. New York, USA; 1989. p. 59-81.

2. Kusum Devi V, Saisivam S, Maria GR, Deepti PU. Design and evaluation of matrix diffusion controlled transdermal patches of verapamil. Drug Dev Ind Pharm 2003;29:495-503.

3. Sherwin BB, Gelfand MM, Brender W. Androgen enhances sexual motivation in females: a prospective, crossover study of sex steroid administration in the surgical menopause. Psychosom Med 1985;47:339-45.

4. Mahmoud MS, Diamond MP, Balon R. Androgen therapy for low female libido. Sex Reprod Menopause 2006;4:52-9.

5. Hollingsworth M, Berman J. The role of androgens in female sexual dysfunction. Sex Reprod Menopause 2006;4:27-32.

6. Basson R. Female sexual response: the role of drugs in the management of sexual dysfunction. Obstet Gynecol 2001;98:350-3.

7. Kingsberg S. Testosterone treatment for hypoactive sexual desire disorder in postmenopausal women. J Sex Med 2007;4:227-34.

8. Kingsberg S, Shifren J, Wekselman K, Rodenberg C, Koochaki P, De Rogatis L. Evaluation of the clinical relevance of benefits associated with transdermal testosterone treatment in postmenopausal women with hypoactive sexual desire disorder. J Sex Med 2007;4:1001-8.

9. Buster JE, Kingsberg SA, Aguirre O, Brown C, Breaux JG, Buch A, Rodenberg CA, et al. Testosterone patch for low sexual desire in surgically menopausal women: a randomized trial. Obstet Gynecol 2005;105:944-52.

10. Shifren JL, Braunstein GD, Simon JA, Casson PR, Buster JE, Redmond GP, et al. Transdermal testosterone treatment in women with impaired sexual function after oophorectomy. $\mathrm{N}$ Engl J Med 2000;343:682-8.

11. Sherwin BB. Randomized clinical trials of combined estrogenandrogen preparations: effects on sexual functioning. Fertil Steril 2002;77:49-54.

12. Ganz PA, Greendale GA. Female sexual desire-beyond testosterone. J Natl Cancer Inst 2007;99:659-61.

13. Ganz PA, Greendale GA, Petersen L, Zibecchi L, Kahn B, Belin TR. Managing menopausal symptoms in breast cancer survivors: results of a randomized controlled trial. J Natl Cancer Inst 2000;92:1054-64.

14. Bancroft J, Loftus J, Long JS. Distress about sex: a national survey of women in heterosexual relationships. Arch Sex Behav 2003;32:193-208.

15. Dennerstein L, Dudley EC, Hopper JL, Guthrie JR, Burger HG. A prospective population-based study of menopausal symptoms. Obstet Gynecol 2000;96:351-8.

16. Nelson HD, Haney EM, Humphrey L, Miller J, Nedrow A, Nicolaidis C, et al. Management of menopause-related symptoms; 2005.

17. Shen WW, Urosevich Z, Clayton DO. Sildenafil in the treatment of female sexual dysfunction induced by selective serotonin reuptake inhibitors. J Reprod Med 1999;44:535-42.

18. Sherwin B. Use of combined estrogen-androgen preparations in the postmenopause: evidence from clinical studies. Int J Fertility Womens Med 1998;43:98-103.

19. Sarrel PM. Effects of hormone replacement therapy on sexual psychophysiology and behavior in postmenopause. J Women's Health Gender-Based Med 2000;9(1, Suppl 1):25-32.

20. Davis SR, Burger HG. Clinical review 82: androgens and the postmenopausal woman. J Clin Endocrinol Metab 1996;81:2759-63.
21. Sarrel P, Dobay B, Wiita B. Estrogen and estrogen-androgen replacement in postmenopausal women dissatisfied with estrogen-only therapy. Sexual behavior and neuroendocrine responses. J Reprod Med 1998;43:847-56.

22. Davis SR, McCloud P, Strauss BJ, Burger H. Testosterone enhances estradiol's effects on postmenopausal bone density and sexuality. Maturitas 1995;21:227-36.

23. LL Brunton, JS Lazo, KL Parker. Eds. Goodman and Gillman's Manual of pharmacology and therapeutics, the McGraw-hill companies. New York; 2006. p. 15.

24. Mukherjee B, Mahapatra S, Gupta R, Patra B, Tiwari A, Arora P. A comparison between povidone-ethylcellulose and povidoneeudragit transdermal dexamethasone matrix patches based on in vitro skin permeation. Eur J Pharm Biopharm 2005;59:47583.

25. Dornish M, Domard A, Roberts GAF, Varum KM.1 Advances in chitin science. In: Eds. Elsevier Applied Science Publication; 1997. p. 664-70.

26. Dodane V, Khan MA, Merwin JR. Effect of chitosan on epithelial permeability and structure. Int J Pharm 1999;182:21-32.

27. Park YJ, Lee YM, Lee JY, Seol YJ, Chung CP, Lee SJ. Controlled release of platelet-derived growth factor-BB from chondroitin sulfate-chitosan sponge for guided bone regeneration. J Controlled Release 2000;67:385-94.

28. Ramanathan S, Block LH. The use of chitosan gels as matrices for electrically-modulated drug delivery. J Controlled Release 2001;70:109-23.

29. Arora P, Mukherjee B. Design, development, physicochemical, and in vitro and in vivo evaluation of transdermal patches containing diclofenac diethylammonium salt. J Pharm Sci 2002;91:2076-89.

30. Guideline IH. Stability testing of new drug substances and products Q1A (R2). Curr Step 2003;4:1-24.

31. Mutalik S, Udupa N. Pharmacological evaluation of the membrane-moderated transdermal system of glipizide. Clin Exp Pharmacol Physiol 2006;33:17-26.

32. Siepmann J, Ainaoui A, Vergnaud JM, Bodmeier R. Calculation of the dimensions of drug-polymer devices based on diffusion parameters. J Pharm Sci 1998;87:827-32.

33. Brochard F, Degennes PG. Kinetics of polymer dissolution. Physicol Chem Hydrodynamics 1983;4:313-22.

34. Bonferoni MC, Caramella C, Sangalli ME, Conte U, Hernandez RM, Pedraz JL. Rheological behavior of hydrophilic polymers and drug release from erodible matrices. J Controlled Release 1992;18:205-12.

35. Ju RT, Nixon PR, Patel MV, Tong DM. Drug release from hydrophilic matrices. 2. A mathematical model based on the polymer disentanglement concentration and the diffusion layer. J Pharm Sci 1995;84:1464-77.

36. Ouano AC, Tu XO, Carothers JA. Dynamics of polymer dissolution. In: FW Harish, RB Seymour. EDs. Structure solubility relationships in polymers, Academic Press: New York, NY; 1997. p. 11-20.

37. Yum SL, Wright RM. Drug delivery based on diffusion and osmosis. In: SD Bruck. ed. Controlled drug delivery-basic concepts. Vol. II. CRC Press: Boca Raton, FL; 1983. p. 65-88.

38. Draize JH, Woodard G, Calvery HO. Methods for the study of irritation and toxicity of substances applied topically to the skin and mucous membranes. J Pharmacol Exp Ther 1944;82:377-90.

39. Das A, Ahmed AB. Formulation and evaluation of transdermal patch of indomethacin containing patchouli oil as natural penetration enhancer. Asian J Pharm Clin Res 2017;10:320-5.

40. Sadhasivam LI, Dey N, Francis AP, Devasena T. Transdermal patches of chitosan nanoparticles for insulin delivery. Int J Pharm Pharm Sci 2015;7:84-8.

41. Jadhav JK, Sreenivas SA. Formulation and in vitro evaluation of indomethacin transdermal patches using polymers HPMC E5 and ethyl cellulose. Int J Pharm Pharm Sci 2012;4:550-6.

42. Allena RT, Yadav HK, Sandina S, Sarat Chandra Prasad M. Preparation and evaluation of transdermal patches of metformin hydrochloride using natural polymer for sustained release. Int J Pharm Pharm Sci 2012;4:297-305. 